\title{
Pela atenção ao comum: entrevista com Muniz Sodré
}

\section{Anelise Angeli De Carli}

Doutoranda; Universidade Federal do Rio Grande do Sul, Porto Alegre, RS, Brasil anelisedecarli@gmail.com

\section{Andriolli de Brites da Costa}

Doutorando; Universidade Federal do Rio Grande do Sul, Porto Alegre, RS, Brasil

andriolli_costa@hotmail.com

\section{Resumo}

A entrevista com Muniz Sodré propõe ao teórico da comunicação algumas perguntas que atravessam a sua proposta de pensamento ampliado para o termo comunicação. $O$ autor fala sobre a linguagem na perspectiva da reflexividade e sobre os efeitos e as limitações do bios midiático. Ainda, Sodré propõe pensar o algoritmo das tecnologias de informação como um tipo de imagem do contemporâneo.

\section{Palavras-chave}

Comunicação. Epistemologia. Teoria da Comunicação.

Ontologia.

No início do seu livro teórico mais recente, Sodré (2014) aponta a necessidade da retomada do entendimento sobre o fenômeno da comunicação. 0 verbo comunicar está ligado ao sentido das ações de vincular, organizar ou, ainda, de deixar-se vincular e organizar pelo que há de comum (SODRÉ, 2014). A função comunicativa que constitui a condição humana deriva desse fenômeno. Como afirmou, em recente palestra em Porto Alegre $^{1}$, os homens não são comunicantes porque falam; a fala é uma questão de linguagem. Os homens são comunicantes porque estabelecem relações ou porque organizam mediações simbólicas, de modo consciente ou inconsciente, em nome da partilha de algo em comum. Essa organização é uma dimensão constituinte do homem e, nas palavras do autor,

\footnotetext{
1 Aula comemorativa dos 50 anos da Faculdade de Comunicação Social (Famecos) da Pontifícia Universidade Católica do Rio Grande do Sul (PUC-RS), em outubro 2016
} 
"atividade pré-subjetiva de ordenamento simbólico do mundo" (SODRÉ, 2016, informação oral).

A recuperação semântica do termo por Sodré, portanto, enfatiza que as mediações simbólicas não se restringem à lógica sintática das palavras. As relações que se estabelecem ao redor do fenômeno da comunicação englobam uma miríade de plataformas para além do verbo, como imagens, corpos e conteúdos inconscientes. Em adicional, Sodré tem retomado em suas falas a perspectiva de pensamento da reflexividade, estabelecendo a premissa de que as ideias criam o mundo que as cria. Nada diferente do que acontece com a própria história das práticas comunicacional que, desde as primeiras interações entre seres humanos, desdobra-se, atualmente, em materialidades e termos técnicos, impactando fortemente a maneira de entendermos, contemporaneamente, o social. Este é o bios sobre o qual Sodré tem falado há alguns anos $(2002,2006,2014)$.

Para tirar consequências dessas colocações, Sodré tem sistematicamente proposto, nos seus últimos textos, a ideia de que, mesmo abandonando o modelo informacional como perspectiva literalmente admitida, o entendimento funcionalista mantém-se nos estudos da comunicação, inclusive nas abordagens que se anunciam mobilizadoras de outras epistemologias, como a semiológica. O problema estaria, então, na ontologia da palavra comunicação.

Embora não seja um pesquisador dedicado literalmente às questões do imaginário, parece que alguns apontamentos feitos por Muniz Sodré problematizam frontalmente questões pertinentes à discussão que movimenta os estudos quando relacionados à comunicação. Quando a perspectiva antropológica do imaginário coloca as imagens como primeiro substrato possível de emanação dos sentidos, ela também desloca a palavra do foco de atenção. Ao mesmo tempo, também, está incluída nessa perspectiva a premissa reflexiva de que os modos de construção do sentido são, eles próprios, definidores e definidos pelos conteúdos que eles comportam. Isto é, a efetivação em signo de certa imagem simbólica não é possível se não compreender um abrandamento de suas arestas pois a imagem não obedece à mesma lógica semântica e sintática que as palavras. Ainda, é justamente devido a essa inadequação, à impossibilidade de materialização completa de conteúdos complexos, que se dá o desenvolvimento de novas plataformas de comunicação de palavras a telas, de ídolos a micropolíticas. A incessante movimentação do bios midiático pode ser entendida, portanto, como uma movimentação das próprias plataformas de 
realização do imaginário que necessita do fenômeno da comunicação pra se efetivar como sensibilidade.

Para entender os pensamentos que circundam a proposta de Sodré e colocá-los em comunicação com algumas ideias propostas pelos estudos do imaginário, algumas perguntas foram propostas.

Em seu livro A ciência do comum, o senhor propõe para o pensamento sobre comunicação as ideias de inteligibilidade e de organização social. Sabemos que midiatização não comporta toda a esfera de sentidos sugerida pelo termo 'comunicação', mas, ao mesmo tempo, ela é a esfera mais visível desse fenômeno nos dias de hoje. Considerando sua ideia de que "a quantidade é um tipo de qualidade", como operacionalizar metodologicamente essa dupla face do bios midiático em nossas pesquisas?

Há de fato uma "dupla face" do bios midiático. Por um lado, esse conceito gira ao redor da indústria do século XXI: a tecnologia da informação, de onde o substrato real do fenômeno pode ser designado como inteligência artificial. Este é o caminho tendencial da apropriação de instituições sociais por organizações de indústria ou pelas burocracias de Estado. Por outro [lado], há os "objetos de menor porte”, abrangidos por uma perspectiva de "sociedade civil", que tem a sua atenção voltada para famílias, comunidades, organizações voluntárias, sindicatos e movimentos de base espontâneos. Nesse outro lado, é preciso considerar a força do vínculo comunitário.

Com o fenômeno da comunicação, colocamos em ação nossa capacidade de articulação de sentidos. Uma das aliadas nessa tarefa de organizar e tornar inteligível a experiência é a linguagem. Poderíamos afirmar que, se a linguagem é ferramenta, ontologicamente ela é um fenômeno segundo ao conteúdo sobre o qual se fala?

A linguagem não é ferramenta sem mais nem menos. Veja o que um pensador como Heidegger diz do grego ao distingui-lo de qualquer outra língua europeia: é logos, ou seja, é uma dicção originária que, ao nomear, cria o que nomeia, o próprio Homem inclusive. Deste modo, enquanto logos, mais fala do que é falada, é uma língua que, dizendo "filosofia", cria a filosofia, logo, ao mesmo tempo, nos diz que cria a história grega. Mas não é apenas o grego, 
como pretende o alemão: a linguagem nos constitui e nos fala, logo, não é ontologicamente secundária a seus conteúdos.

Ao refletir sobre imaginário e sua captura pelo bios midiático, o senhor propõe que a informática computacional é capaz de materializar as imagens em um fluxo informacional. Por outro lado, Merleau-Ponty, em A Prosa do Mundo, lembra-nos das limitações compreensivas dos algoritmos, que "jamais dirão a não ser o que se convencionou fazê-los dizer". Quais dimensões do imaginário escapam ao bios midiático? Seria ele capaz de compreender a subjetividade que é transcendência?

Veja só, a imagem em circulação está no centro do processo de mudanças qualitativas em termos de configuração social por efeito da articulação da tecnologia eletrônica com a vida humana, à qual subjaz a lógica dos algoritmos e cuja superfície é a imagem, a ser entendida lato sensu como visualidade e como imaginário sociocultural. 0 mundo-imagem é a superfície da globalização, mas, diferentemente do passado, o objetivo não é olhar criticamente sob a superfície e, sim, ampliar, pela circulação, a imagem, assim como se faz ampliar e circular o capital financeiro. Nessa ordem de coisas, a imagem vai perdendo a sua força reflexiva e, cada vez mais, ajustando-se à lógica dos enunciados linguísticos. 0 algoritmo é o extremo desse tipo de imagem. Ele ainda nada sabe de subjetividade.

Em uma palestra recente na Universidade do Vale do Rio dos Sinos (Unisinos) ${ }^{2}$, o senhor abriu sua fala com a parábola do sapo e da panela de água quente. A partir dela, refletiu sobre como nosso objetivo, enquanto gênero humano, seria o de não sermos devorados pelo mar tecnológico, tal qual o sapo paulatinamente escaldado pelas águas cuja temperatura só faz subir. No entanto, se a escolha de mergulhar nesse mar diluvial da informação e da tecnologia foi feita coletivamente, como podemos resistir a sermos tragados por ele? De que formas a Comunicação pode ser uma resposta para isso?

Sim, eu estava falando de Alan Kay, às vezes descrito como o pai intelectual do microcomputador, que fez soar um alerta com uma analogia que parecia valer para nós. Era a velha história do sapo: se botarmos o bicho numa panela com água e formos subindo a

${ }^{2}$ Seminário Internacional de Midiatização, dezembro de 2016. 
temperatura aos poucos, o sapo não vai pular fora nem quando a água estiver fervendo, pois seu sistema nervoso não capta pequenas mudanças de temperatura. 0 que a comunicação pode fazer pelo sapo? Nada, creio. 0 que normalmente se entende como comunicação é precisamente essa água na panela que escalda o sapo. Bem, pode-se entender comunicação de outra maneira, acho que é disso que eu falo também em $A$ ciência do comum.

O ato de comunicar-se nos permite o prazer do vínculo, e a forte adesão à internet, provocada pela conexão que ela nos oferece, parece mostrar isso. Ao mesmo tempo em que amplia as potencialidades comunicativas, o bios midiático tem criado espaço para o desenvolvimento do consumismo, como se estivesse em ação uma motriz objetificadora que apaga as relações eutu e privilegia as relações eu-isto. Como podemos pensar este paradoxo?

Não há paradoxo. Basta invocarmos o conceito de comunidade (ação recíproca entre agente e paciente, portanto, comunicação enquanto ser-em-comum, vinculação fusional entre um eu e outro), para dar margem à expansão de seu escopo até a dimensão coletiva, onde a vinculação aparece como a radicalidade da diferenciação e da aproximação entre os seres humanos, e daí, como a estratégia sensível que institui a essência do processo comunicativo, este que John Dewey chamava de "interação comunal". Aqui na ECO/UFRJ [Escola de Comunicação da Universidade Federal do Rio de Janeiro], a professora Raquel Paiva vem trabalhando nesta perspectiva no âmbito da comunicação comunitária.

Em As estratégias sensíveis, encontramos uma reflexão acerca do crescente protagonismo da estética como recurso de produção de sentido no contexto contemporâneo da comunicação midiatizada. A estética pode ser pensada como um meio de produzir conhecimento no contexto de hiperconexão ou a ideia aristotélica da imagem como mediadora do saber não tem mais validade nos dias de hoje? Seria necessária, também, uma problematização ontológica para a imagem, assim como proposta para a comunicação?

Em Aristóteles, a imagem (phantasma) é uma mediação sem a qual a alma não pode conhecer. Na mediação clássica, imagem é algo que se interpõe entre o indivíduo e o mundo para construir o conhecimento; na midiatização, desaparece a ontologia substancialista dessa correlação, e o indivíduo (ou o mundo) converte-se, ele próprio, em imagem gerida por um código tecnológico. Nesta nova chave conversora do real, em realidade compatível 
com a lógica organizacional (no limite, o mercado como nova teodicéia), a própria ideia de mediação se enfraquece. Quero crer que, nesse livro meu a que você se refere, está dada uma problematização da imagem.

Como o senhor avalia o estado atual do pensamento brasileiro sobre a Comunicação, no que se refere às questões da imagem?

Eu acho que os pesquisadores brasileiros da área da comunicação têm se debruçado mais sobre a visualidade em sentido amplo (que inclui as figurações da internet), do que a imagem entendida como comunidade de sentido compartilhado (Rancière). São vários os nomes de interesse, principalmente, no campo da fotografia, que muito se destaca.

Em 2016, "pós-verdade" (post-truth) foi eleita pela Oxford Dictionaries a palavra do ano. No contexto da internet, uma plataforma multimidiática, onde o compartilhamento ocupa a centralidade, poderíamos pensar a pós-verdade como uma estética em ação?

Slavoj Žižek sustenta, há bastante tempo, que, hoje em dia, a verdade teria "a estrutura de uma ficção". Não vejo isso como uma estetização sem mais nem menos e, sim, como o deslocamento de palavras e conceitos rumo à sua neutralização política e social. Ficcionalizam-se os significados para esvaziá-los. Isso, por um lado. Por outro, conferir à verdade uma estrutura de ficção pode significar que temos de inventar ou reinventar comunitariamente as verdades. Não é o poeta Manuel de Barros quem dizia "tudo que não invento é falso"?

Por falar em invento, Muniz Sodré também é um autor de ficção. Em que medida podemos relacionar sua obra literária com sua obra teórica? A teoria também é uma forma de produzir ficção?

Teoria vem de "theorein", que significa contemplar, ver. Epistemicamente ou ficcionalmente, estamos sempre contemplando o mundo, embora com diferentes formas de olhar ou de contar. Eu gosto de escutar e de contar historias. É possível produzir conceitos na obra literária. Aprende-se mais com Machado de Assis do que a maioria dos teóricos de sua época ou de depois. 
O senhor possui uma trajetória que atravessa áreas diversas do conhecimento, como o Direito, a Literatura, a Antropologia e a Sociologia. O pensamento ampliado sobre o fenômeno da comunicação se deve de algum modo a esse seu livre trânsito por diferentes perspectivas?

Eu não acredito em fronteiras disciplinares. Acredito, sim, em limiares, que são pontos movediços de limites. O limiar convida ao ultrapasse. Você acaba chegando ao que Marx chamava de "continente da Historia". Se é possível atribuir uma virtude epistemológica ao campo da comunicação, ela tem a ver com a liquefação das barreiras "alfandegárias". Perdão, [barreiras] disciplinares, do conhecimento.

\title{
Referências
}

SODRÉ, Muniz. Antropológica do espelho: uma teoria da comunicação linear e em rede. Petrópolis: Vozes, 2002.

SODRÉ, Muniz. As estratégias sensíveis: afeto, mídia e política. Petrópolis: Vozes, 2006.

SODRÉ, Muniz. A ciência do comum: notas para o método comunicacional. Petrópolis: Vozes, 2014.

SODRÉ, Muniz. Aula magna - 50 anos Famecos/PUC-RS. 5 out. 2016. Disponível em: <https://www.youtube.com/watch?v=eC5-RAKuNz8\&>. Acesso em: 29 mar. 2017.

\section{Minding the common: interview with Muniz Sodré}

\begin{abstract}
In this interview, Muniz Sodré proposes to the communication theorist some questions that cross his proposal of extended thinking of the term communication. The author talks about language in the perspective of reflexivity and on the effects and limitations of the media bios. Moreover, Sodré proposes to think about the algorithm of information technologies as a contemporary type of image.
\end{abstract}

\section{Keywords}

Communication. Epistemology. Image. Ontology. Theory.

Recebido em: 30/03/2017

Aceito em: 01/05/2017 